\title{
Utilizing Service Science to Construct Green Printing Industry
}

\author{
Chen Hejie \\ Economical and Management Department, \\ Beijing Institute of Graphic Communication, \\ Beijing, CHINA \\ chenhejie81@sina.com
}

\author{
Huang Xiaozhang \\ Economical and Management Department, \\ Beijing Institute of Graphic Communication, \\ Beijing, CHINA
}

\begin{abstract}
The Green printing has the followed three characteristics: the lower environment impact, the less pollution, saving resources and energy of the printing. Many printing produces are deserted in china every year. With the development of IT technology and communication technology, digital printing appeared. In fact, digital printing is a kind of green printing. However, high efficiency digital printing relied on knowledge management. The digital printing flow can be divided into some parts. Every part formed service. The service science and ontology are used in the digital printing. This paper presented a green digital printing framework. And ontologies are used in the green printing.
\end{abstract}

Keywords-Digital pinting;Green printing;Service science; Ontolgoies;knowledge management

\section{Introduction}

With China affiliated WTO, international and domestic competition of press and publication is constantly intense. According to the General administration of Press and Publication of The P. R. China Report, china published 274123 kinds' books and 7062 million volumes in 2008[1]. Form many statistic data, more and more people read writing from computer, digital library, network and mobile devices. Reading habits diversify to influence the press and publication. According to statistics, the adult of reading rate is $49 \%$, but $61 \%$ of the population aren't satisfied with reading. According to statistics data published in 2009, China's digital publishing production value is equal to the traditional press. China's digital publishing predicted to remain more than 50\% annual growth.

Green printing firstly emerged some developed countries (for example, Japan, the United States, Germany and other Western developed countries) in the late 1980. With the technology development, green printing has been developed from the concept stage to the application stage [2]. The principles of green printing included reduced the number of printing produces and reused resources. Other realization method of green printing is digital printing process.

Digital printing indicated the new printing process which collected digital graphic information, processed electronic documents to directly image on paper and other printed materials by computer, and needed not any intermediate manual proofing [3].
In order to implement green printing, some advanced technologies are adopted. This paper described a method that service science is used in the green printing.

Today many companies (for example IBM) find that services are the fastest growing parts of their business. The service value continually increased. Service ideal deeply impacted on the enterprise management. Specialized research domain - service science - is born. Printing and publishing industry has been concerned about this area research. The printing plants have many problems on technology process and management of green printing. But service science built a virtual group through services to facility green printing.

This paper describes the use of services science and semantic web to build high-performance digital printing industry infrastructure. We apply ontology and service science to build a service-oriented digital printing platform. The paper is structured as follows. Section II introduced green printing and digital printing. Section III introduced technology background. Section IV outlined some ontologies implemented digital printing. Section V provided the conclusions and the future works.

\section{Green Printing and digital Printing Background}

\section{A Green Printing}

Green printing firstly emerged some developed countries (for example, Japan, the United States, Germany and other Western developed countries) in the late 1980. With the technology development, green printing has been developed from the concept stage to the application stage.

The principles of green printing included reduced the number of printing produces and reused resources. The characteristics had low power consumption, low emission and high efficiency. In order to reduce energy consumption and pollution, green printing based on environmental standards, promoted energy conservation and products, researched new materials, exploited new technical process.

Other realization method of green printing is digital printing process, which included green office system, Enterprise Collaborative System and Enterprise Resource Planning. Information system fulfilled to reduce enterprise cost and emission. 


\section{B Digital Printing}

Digital printing indicated the new printing process which collected digital graphic information, processed electronic documents to directly image on paper and other printed materials by computer, and needed not any intermediate manual proofing.

If digital printing combined with Internet, a global printing service system elected that didn't constrain the distance and time limit. The global printing service system provided personalized, on-demand printing system, and open up a new market. The emergence of digital printing produced a series of new printing concepts, for example on-demand printing, color digital printing, variable data printing, personalized printing, remote printing and so on.

Digital printing has some typical features.

- $\quad$ Entire digital printing process. Digital printing process printed the digital file directly to paper/printing produces. This is a fully digital production process. Working procedure didn't require film and printing plates, without the traditional printing processes.

- $\quad$ Remote printing.

- Variable information printing. Information of digital printing produces can $100 \%$ variable information, which the output of two sequential prints can be completely different.

\section{Technology Background}

\section{A The Semantic Web}

The Semantic Web is described as "an extension of the current Web in which information is given well-defined meaning, better enabling computers and people to work in cooperation." The Semantic Web must have proof that it finishes to trust the information, and then it correlate with the other information that people have. Finally we take advantage of this new knowledge [4].

The Semantic Web offered semantic annotations that explicitly described Web resource. These annotations are built on ontologies, representing domain through their concepts and semantic relations between them. Ontologies are the foundations of the Semantic Web and the keystone of the Web's automated tasks_-searching, merging, sharing, maintaining, customizing and monitoring [5].

\section{B Ontology}

Ontology is the term used to refer to the shared understanding of some domain of interest. Or ontology is an explicit account or representation of a conceptualisation.

Ontology necessarily entails or embodies some sort of world view with respect to a given domain. The world view is often conceived as a set of concepts, their definitions and their inter-relationships. Such a conceptualisation may be implicit or embodied in a piece of software [6].

\section{Service Science}

The term "services" usage arose out of the 1930s U.S. Department of Commerce's Standard Industrial Classification
(SIC) codes. At that time, services was a residual category for other activities that did not fit into agriculture or manufacturing [7].Today, Ted Hill, an influential scholar, suggested that: "A service is a change in the condition of a person, or a good belonging to some economic entity, brought about as the result of the activity of some other economic entity, with the approval of the first person or economic entity."[8]

Today many companies find that services are the fastest growing parts of their business and use some service systems. Service systems are value-co-creation configurations of people, technology, value propositions connecting internal and external service systems, and shared information. Service science is the study of service systems, aiming to create a basis for systematic service innovation. Service science combines organization and human understanding with business and technological understanding to categorize and explain the many types of service systems that exist as well as how service systems interact and evolve to co-create value [9].

\section{A Green Digital Printing Framework}

Figure 1 described a digital printing flow. Service science is used in the second and the third part.

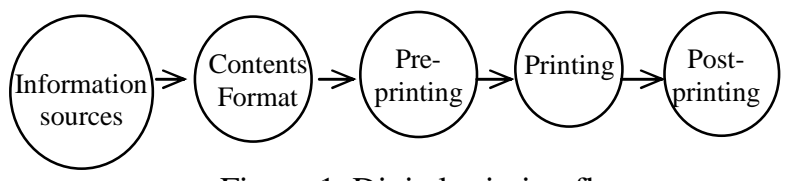

Figure 1. Digital printing flow

Figure 2 described a green digital printing framework. The Service platform provided service-base to combined different services. An organization provided different some printing functions. Service combined a virtual organization according to printing requirements. One organization or some organizations implemented these printing requirements.

In order to achieve the knowledge management of digital printing, ontology is applied this project. Ontology implemented knowledge description, knowledge share and knowledge management. This paper mainly introduced the service-oriented ontology which is a part of green printing.

The base layer is composed of inventory management, financial management, production management, sale management and human management. These components implemented some functions of a printing plant. These functions are basic requirements of green digital printing.

The upper layer of the base layer accomplished knowledge description, knowledge share and knowledge management.

Service platform provided service-base to combined different services. Different services combined according to semantic description.

The highest layer described diverse printing form. 


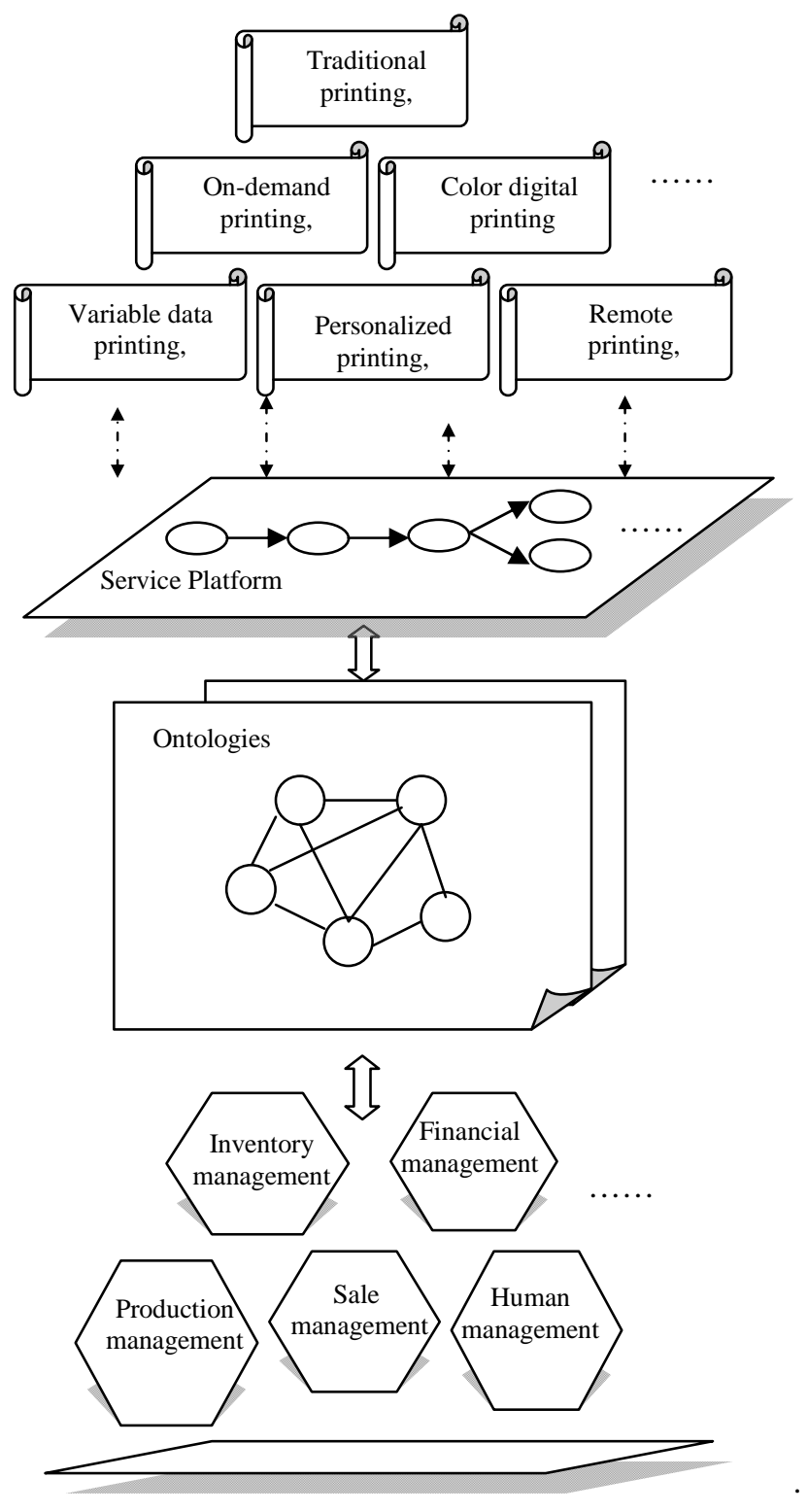

Figure 2.Green digital printing framework

\section{Ontologies Specification of Digital Printing}

Ontology implements knowledge share and knowledge management. The publishing digital products process Ontology contained the concepts, relationships between concepts and constraints based on the concepts. We use UML tool to specify ontology [10].In this paper, we mainly described three ontologies.

In order to achieve the knowledge management of digital printing, ontology is applied this project. Ontology implemented knowledge description, knowledge share and knowledge management. This paper mainly introduced the service-oriented ontology which is a part of green printing. And the paper introduced these ontologies functions. The printing plant ontologies are the base of digital printing process.
1) The Digital Printing Ontologies has been designed based on four criteria:

2) The Digital Printing Ontologies roundly describes main issues of digital printing.

3) The Digital Printing Ontologies must be associated with the practical application.

4) The Digital Printing Ontologies must well compatibility with the existing standards and ontologies.

5) The Digital Printing Ontologies has good extensibility.

Digital printing ontologies are divided into three parts: Digital Printing Flow ontologies, Digital Printing ontologies, and Process ontologies.

- Digital Printing Flow ontologies: digital printing work ontology, digital printing component ontology, digital printing item ontology

- Digital Printing ontologies: digital printing products ontology, copyright ontology, digital format ontology

- Process ontologies: step ontology, participants ontology

And service ontology and service combined ontology implemented service functions of green digital printing.

\section{A Service Ontology}

Service participant ontology mainly described service that the special printing plant needed digital printing service. Name described the special service. The value of enterprise is enterprise name. Functions introduced this service functions. Requirements described this service require printing functions.

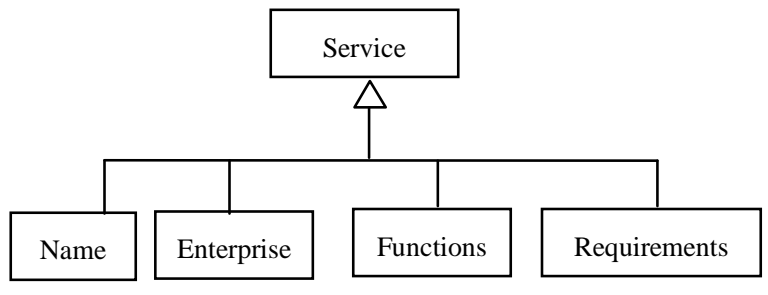

Figure 3.Service ontology

\section{B Service Combined Ontology}

Service combined ontology described different services to form digital printing part which are consumed by the follow printing step. Name described service name. Source name is service provider called service term. Description is service introduction. Price marked service charge. Judgment noted the quality of the finished job. Judgment Indicated whether the services to achieve customer satisfaction.

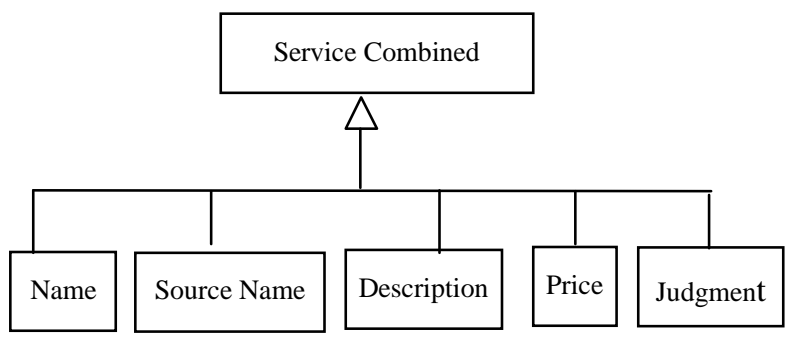

Figure 4.Service combined ontology 


\section{Conclusions}

A realization method of green printing is digital printing process. This paper presented a green digital printing framework. The high efficiency digital printing relied on knowledge management and service science. Ontology is the term used to refer to the shared understanding of some domain of interest. Or ontology is an explicit account or representation of a conceptualisation. The paper introduced the printing plant that utilized digital printing ontologies. In the future, we focused on other ontologies of green digital printing.

An organization provided different some printing functions. Service combined a virtual organization according to printing requirements. One organization or some organizations implemented these printing requirements.

\section{Acknowledgment}

This research was supported by the Key Research Project of Beijing Institute of Graphic Communication under contract with No. 23190111044.

\section{References}

[1] "2008 press and publication Statistic information of the People's Republic of China, ” http://www.gapp.gov.cn/cms/html/21/464/ 200907/465083.html

[2] Gu Meili, "Printing has become an important part of the information industry, ” science \& technology information,2011 NO.01,pp210-211

[3] Liu Xunting, “Green printing is imperative Guangdong Printing,’2011,pp 7-10

[4] Hejie Chen, Ben Liu, Wei He, "IQS: An Inferable Query Service for Semantic Web," Proceedings of the International Conference on Communication and Information 2005, Publishing House, BUPT, pp.876-879

[5] Olivier Corby, Rose Dieng-Kunta etc, "Searching the Semantic Web: Approximate Query Processing Based on Ontologies, ” IEEE Intelligent System, Jan/Feb 2006, pp.20-27

[6] Mike Uschold \& Michael Gruninger, “Ontologies:Principles,Methods and Applications.Knovledge Engineering Review,”Volume 11 Number 2,June 1996

[7] Metcalfe, J.S, "Modern evolutionary economic perspectives: An overview.Frontiers of Evolutionary Economics”, J.S. Metcalfe and K. Dopfer, Eds.Edward Elgar, 2001.

[8] Hill, T.P, “ On goods and services”, The Review of Income and Wealth 23, 4(1977), 314-339.

[9] Paul P. Maglio \& Jim Spohrer, "Fundamentals of service science”, Journal of the Academy of Marketing Science,Volume 36, Number 1.

[10] Cranefield and M. Purvis, “UML as an ontology modeling language”,In Proceedings of the Workshop on Intelligent Information Integration, 16th International Joint Conference on Artificial Intelligence,1999. 